\title{
Brain Development in Childhood
}

\author{
Yasuyuki Taki ${ }^{1,2,3}$ and Ryuta Kawashima ${ }^{2,4,5}$
}

${ }^{1}$ Division of Meidcal Image Analysis, Department of Community Medical Supports, Tohoku Medical Megabank Organization, Tohoku University, Sendai 980-8575, Japan

${ }^{2}$ Division of Developmental Cognitive Neuroscience, Institute of Development, Aging and Cancer, Tohoku University, Sendai 980-8575, Japan

${ }^{3}$ Department of Radiology and Nuclear Medicine, Institute of Development, Aging and Cancer, Tohoku University, Sendai 980-8575, Japan

${ }^{4}$ Smart Ageing International Research Centre, Institute of Development, Aging and Cancer, Tohoku University, Sendai 980-8575, Japan

${ }^{5}$ Department of Functional Brain Imaging, Institute of Development, Aging and Cancer, Tohoku University, Sendai 980-8575, Japan

\begin{abstract}
Although human brain development continues throughout childhood and adolescence, it is a non-linear process both structurally and functionally. Here we review studies of brain development in healthy children from the viewpoint of structure and the perfusion of gray and white matter. Gray matter volume increases and then decreases with age, with the developmental time of the peak volume differing among brain regions in the first and second decades of life. On the other hand, white matter volume increase is mostly linear during those periods. As regards fractional anisotropy, most regions show an exponential trajectory with aging. In addition, cerebral blood flow and gray matter volume are proportional at similar developmental ages. Moreover, we show that several lifestyle choices, such as sleeping habits and breakfast staple, affect gray matter volume in healthy children. There are a number of uninvestigated important issues that require future study.
\end{abstract}

Keywords: Development, Children, Gray matter, White matter, Voxel-based morphometry, Diffusion tensor imaging, Magnetic resonance imaging, Arterial spin labeling.

\section{INTRODUCTION}

In the last ten to fifteen years, progress in magnetic resonance imaging (MRI) and other imaging techniques, the application of statistical analysis to brain imaging, and other advances have enhanced our understanding of brain development, which continues throughout childhood to adolescence and early adulthood. Pediatric brain development is a complex process that includes both linear and non-linear structural and functional processes [1-5]. The initial increase in the number of synapses per neuron and intracortical myelination in the brain is followed by a decrease with maturation, as seen in postmortem studies [68]. In addition, recent neuroimaging studies have determined that several disorders, such as autistic spectrum disorder, show significant differences in gray matter volume both in the cortex [9-11] and in subcortical regions [10] compared with age-matched healthy children. Other studies have identified different trajectories in the correlation between

*Address correspondence to this author at the Division of Meidcal Image Analysis, Department of Community Medical Supports Tohoku Medical Megabank Organization Tohoku University 4-1 Seiryocho, Aobaku, 9808575 Sendai, Japan; Tel: +81-(0)22-717-8457; Fax: +81-(0)22-717-8457; E-mail: ytaki@idac.tohoku.ac.jp white matter volume and age in patients with these disorders compared with age-matched healthy children $[12,13]$. Therefore, understanding brain development in healthy children is thought to be important not only for improving understanding of the progress of brain maturation but may also facilitate early diagnosis and evaluation of developmental disorders, such as autistic spectrum disorders.

Here we review studies of brain development in healthy children, from the viewpoints of gray matter and white matter volume, and brain perfusion. We also review studies that focus on lifestyle factors that are thought to affect brain development. Finally, we point out several uninvestigated important issues in this field.

\section{GRAY MATTER DEVELOPMENT}

Recent studies have shown an inverted-U-shaped correlation between gray matter volume and age, with a preadolescence increase followed by a post-adolescence decrease in healthy children [1-3, 14-17], corresponding to an increase in the number of synapses per neuron and intracortical myelination in brain maturation and then a subsequent decrease $[6-8,18]$. A recent study analyzing the linear and curvilinear trajectories of gray matter density with age in cortical regions showed that higher-order association 


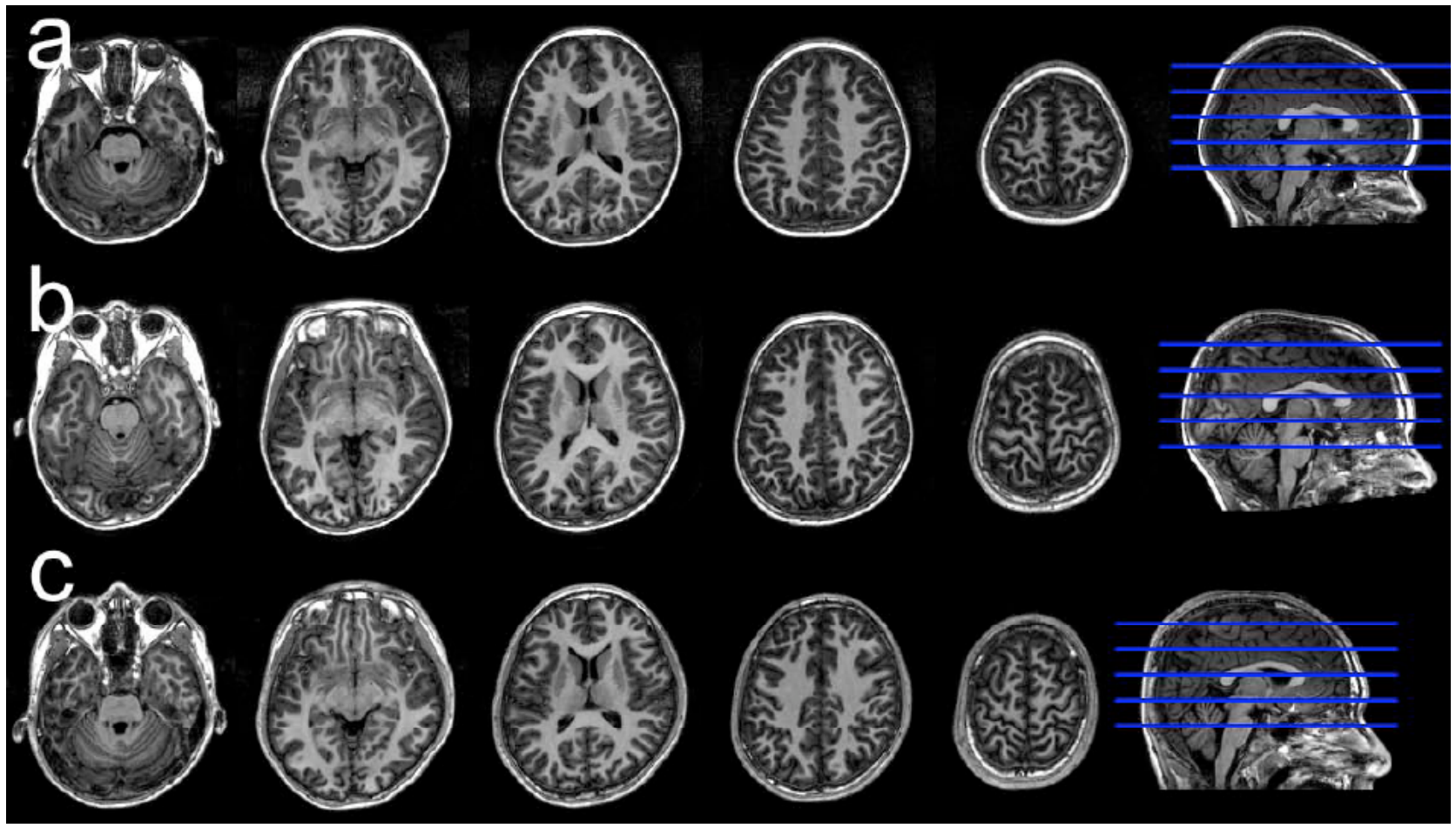

Fig. (1). Representative sets of structural images in a 5.8-year-old female, a 9.6-year-old male, and a 13.5-year old male.

cortices mature only after lower-order somatosensory and visual cortices [3]. Other studies have shown a significant positive linear correlation between gray matter volume and age in several regions, such as the bilateral anterior temporal cortex and insulae, and a significant negative linear correlation between gray matter volume and age in other regions, such as the basal aspect of the frontal lobe and posterior parietal cortices $[19,20]$ using voxel-based morphometry (VBM) [21]. VBM is an established automated neuroimaging technique that enables cortical and subcortical gray matter analysis without a priori identification of a region of interest, which is, therefore, not biased toward any specific brain region. More recently, linear and curvilinear correlations between cortical thickness and age were estimated in cortical gray matter regions using data from 375 healthy children and adolescents [22]. They revealed that cortical regions with simple laminar architecture, including most limbic areas, showed a linear trajectory with age, while poly-sensory and high-order association cortical areas that have complex laminar architecture have the most complex developmental trajectories fitted by quadratic or cubic polynomial functions. Another study showed curvilinear regional cortical thinning with age in adolescence and young adulthood [23]. Cortical thinning was observed across almost the entire cortical mantle. In the majority of regions, cortical thickness decreased non-linearly, with the greatest change occurring in adolescence. The percentage decrease in thickness was largest in the parietal lobe, followed by the medial and superior regions in the frontal lobe, the cingulum and the occipital lobe. Moreover, a recent study analyzed the linear and curvilinear correlations between age and subcortical gray matter regions such as the caudate head, putamen, and thalamus, and found that there were no age effects on thalamic volume, whereas the hippocampus and amygdala showed volume increases [24].
In addition, in our recently published study, we analyzed the linear and curvilinear correlations between gray matter volume and age and between gray matter density and age in cortical and subcortical gray matter using voxel-based analysis applying the Akaike information criterion (AIC). The AIC is one of the methods that are widely used to determine the best-fit model for any correlation by selecting the function that shows the lowest AIC value [25]. Representative sets of structural MR images in a 5.8-yearold female, a 9.6-year-old male, and a 13.5-yearold male are shown in Fig. (1). We found that several regions, such as the lateral frontal cortex, precentral gyrus, and cerebellum, had significant positive linear or curvilinear correlations between gray matter volume and age [26]. We also found several regions, such as the medial aspect of the frontal cortex, that showed significant decreasing linear or curvilinear correlations between gray matter density and age [26]. Thus, recent studies have revealed the trajectory of gray matter volume or cortical thickness with age. These studies may help in clarifying the mechanisms of normal brain maturation from the viewpoint of brain gray matter volume and enable a distinction between normal and abnormal gray matter volume trajectories indicative of developmental disorders.

\section{DEVELOPMENT OF WHITE MATTER}

In addition to gray matter volume, white matter volume also has a curvilinear trajectory with age in childhood through adolescence, with a stable preadolescence volume followed by a slight post-adolescence increase [2, 23, 27 $29]$. The increase and decrease in the number of synapses per neuron and intracortical myelination in brain maturation are believed to contribute to this phenomenon $[6-8,18]$. Recent studies have focused on white matter microstructure, such as fractional anisotropy (FA) and mean diffusivity (MD), using 


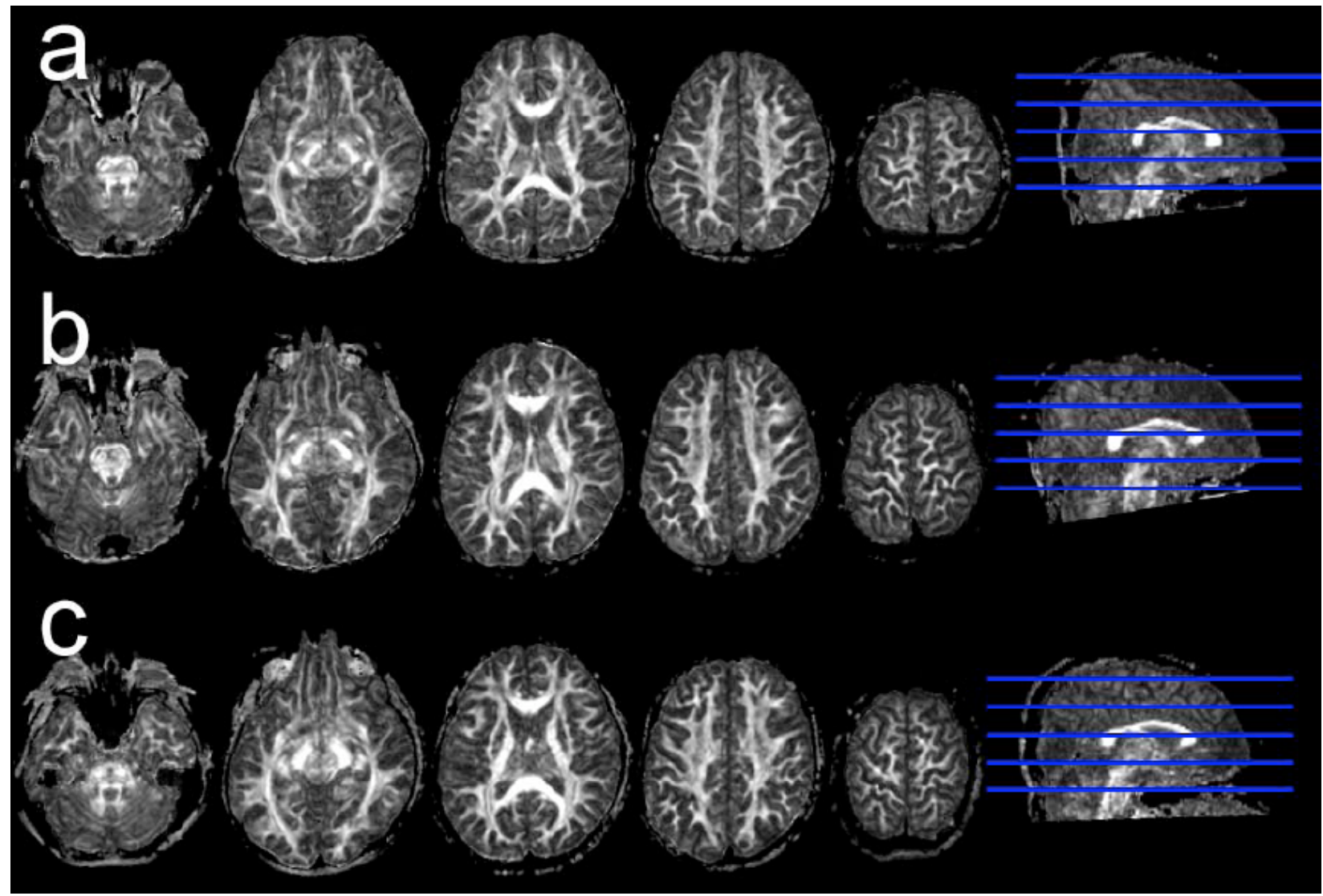

Fig. (2). Representative sets of FA map in a 5.8-year-old female, a 9.6-year-old male, and a 13.5-year old male.

diffusion-tensor imaging (DTI). DTI indirectly provides in vivo information about tissue microstructures using the random diffusion of water molecules in the brain [30]. While the FA index is a commonly used intravoxel metric that characterizes the degree of diffusion directionality [31], FA is a measure of the directionality of diffusion, with values ranging from 0 (isotropic diffusion) to 1 (totally anisotropic diffusion), and is sensitive to axonal diameter, axonal density, and the degree of myelination [32-34]. On the other hand, MD measures the average degree of water diffusion. Several studies have shown that while FA increases linearly with age, MD decreases linearly from childhood to young adulthood [35-39]. However, other recent studies have shown that the FA and MD trajectories are curvilinear, rather than linear, such that FA initially increases rapidly with age, and then the rate of increase slows, finally reaching a plateau. In contrast, MD initially decreases rapidly with age, then the rate of decrease slows, and finally a stable value is reached. The correlations of curvilinear fitting, using exponential fitting, in ROI analysis [23, 27, 40-42] have been estimated. ROI analysis has the advantage that the developmental change of specific white matter fibers can be the research focus. On the other hand, voxel-based analysis has the advantage of revealing brain maturation in whole brain regions, without setting any a priori ROI. In a recently published paper, we examined linear and curvilinear correlations of FA, MD, and white matter volume with age in a large number of healthy children using brain structural and diffusion-tensor MRI followed by voxel-based and ROI analyses. Representative sets of FA map in a 5.8-year-old female, a 9.6-year-old male, and a 13.5-yearold male are shown in Fig. (2). We found that the correlations of FA and MD with age showed exponential trajectories in most ROIs, except for a few fibers, such as the corpus callosum connecting the bilateral rectal gyri in boys [43]. Furthermore, the correlation between white matter volume and age was generally positive and linear in most ROIs, except for a few fibers, such as the bilateral uncinate fasciculus. Additionally, the maturational rate differed among major fibers. In girls, the left superior longitudinal fasciculus, which connects the frontal and temporal lobes, showed a slower rate of maturation than other fibers [43].

Because the FA value is associated with cognitive functions such as reading skills [44] and working memory [45], correlating measures of white matter microstructure and age in healthy children is important. Additionally, subjects with autism show lower FA in several regions, such as the superior temporal sulcus and the fusiform gyrus [36]. Thus, defining the normal trajectory of the correlation between FA and MD with age in the whole white matter may clarify white matter maturation relative to cognitive function in healthy children, and also explain differences in brain maturation between healthy children and children with autism.

\section{DEVELOPMENTAL CHANGES IN CEREBRAL BLOOD FLOW}

Despite a growing wealth of knowledge about maturational changes in gray/white matter volume and white matter microstructures in children, brain perfusion with age in healthy children is not yet well documented. Brain perfusion is thought to reflect cerebral metabolic demand 


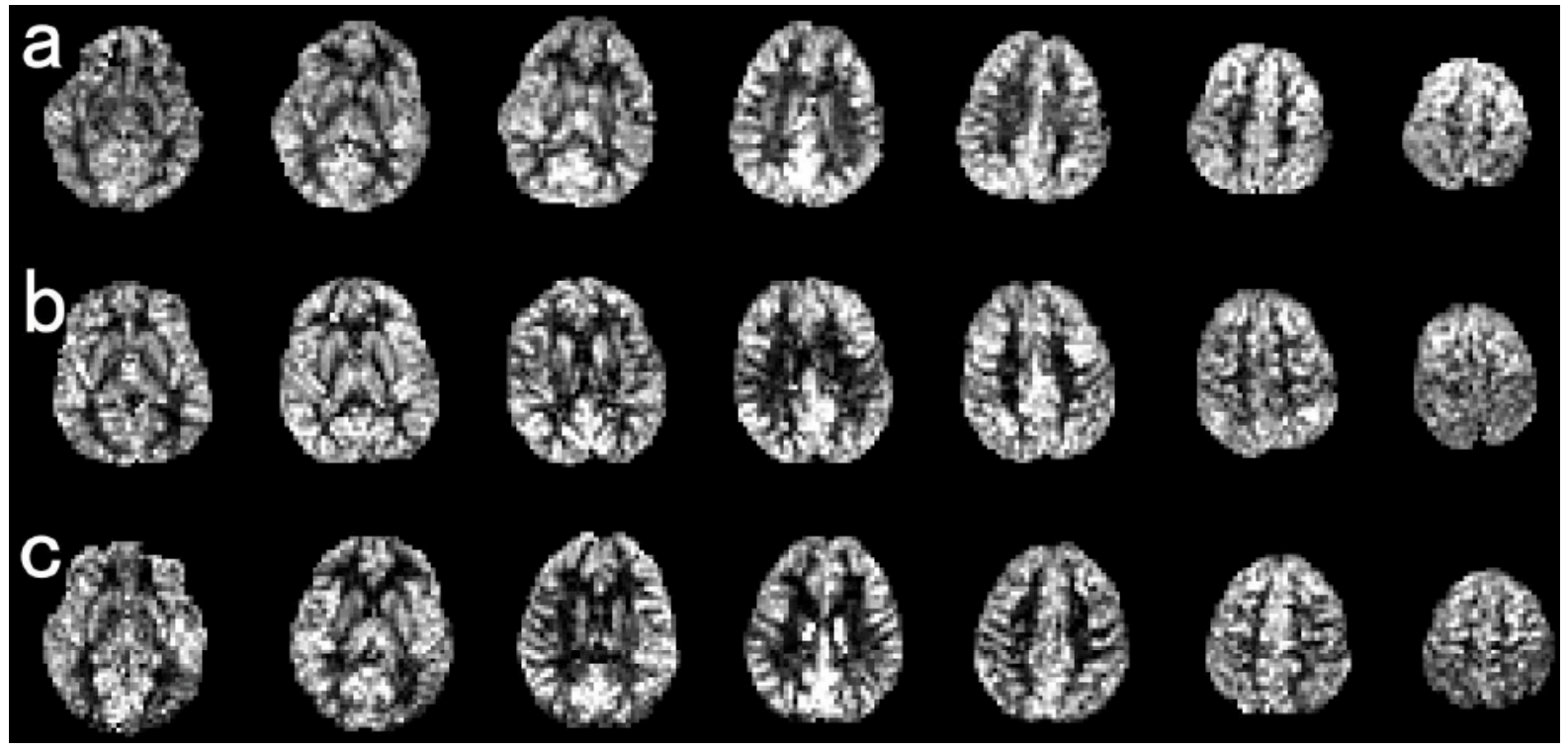

Fig. (3). Representative sets of ASL images in a 5.8-year-old female, a 9.6-year-old female, and a 13.5-year old female (adopted from [61]).

[46], and several disorders such as autism show significant differences in brain perfusion compared with age-matched normal children [47-49]. Earlier brain perfusion has been measured by intravenous bolus injection of contrast agents or radioisotopes. More recently, arterial spin-labeling (ASL) perfusion MRI was developed for evaluating brain perfusion [50]. In ASL, arterial blood water is magnetically labeled proximal to the tissue of interest, and the effects of this prelabeling are determined by pair-wise comparison with images acquired using control labeling. This technique provides reproducible and reliable quantitative measurements of brain perfusion in various diseases and psychiatric disorders in adults [51-55]. Because of the higher water content in children, as compared to adults [56], and higher blood-flow rates in carotid arteries in children, as compared to adults [57], the limitations of low signal-tonoise ratio and transit effects in ASL are reduced in children, as compared to adults [58]. Using ASL, one study showed a correlation between brain perfusion and age from 4 to 78 years [59]. Perfusion in gray-matter volume in the first decade of life was about two times higher than in adults; decreased in adolescence, and finally reached the adult level [59], consistent with a study applying ${ }^{15} \mathrm{O}$-labeled positron emission tomography [60]. We recently reported a correlation between brain perfusion, adjusted for gray-matter density, and age in a large number of healthy children with a wide age range. We applied ROI analysis, in which cerebral gray-matter was divided into four lobes and 22 ROIs, corresponding to anatomical structures in each hemisphere [61]. Because of the limited spatial resolution of ASL, and significantly higher brain perfusion in gray matter compared with white matter, we adjusted gray matter density in brain perfusion to remove the partial volume effect between perfusion of gray and white matter [62]. Representative sets of ASL images in a 5.8-year-old female, a 9.6-year-old male, and a 13.5-yearold male are shown in Fig. (3). We found that BP-GMD showed an inverted-U- followed by a U-shaped curvilinear pattern in most brain regions, similar to the trajectories derived from brain structural and functional studies with respect to brain maturation $[3,6,46]$. In addition, we showed that the age of the highest BP-GMD differed among the lobes and gray-matter regions, progressing from the occipital lobe to the frontal lobe via the temporal and parietal lobes.

As regards the curvilinear pattern, a pre-adolescence increase followed by a post-adolescence decrease in the number of synapses per neuron and intracortical myelination occur during brain maturation $[6-8,18]$. This may affect the results as seen in the correlations between gray matter volume and age described above. Because a major portion of the brain's glucose consumption is used for the maintenance of resting membrane potentials [63], there should be a direct relationship between the degree of synaptic connectivity, or dendritic arborization, and the cerebral metabolic rates of glucose utilization (CMRglu). In fact, the trajectory of CMRglu in the first and second decades of life increases twice as much as that seen during the first four to ten years, and then shows a gradual decline until adult CMRglu values are reached around the age of 16-18 years [46]. Due to the relationship between CBF and glucose consumption [64-66], an inverted-U- followed by a U-shaped curvilinear trajectory of BP-GMD is observed in healthy children. Several postmortem studies of human brains showed that the time course of synaptogenesis was earlier in the visual cortex and auditory cortex than in the prefrontal cortex [6-8], with the age of the highest BP-GMD moving in a posterior to anterior direction. Moreover, synapse elimination starts earlier in the visual cortex than in the auditory cortex, whereas synapse elimination in the prefrontal cortex starts later than in the visual cortex and the auditory cortex [6]. Therefore, brain maturation starts in the occipital lobe, and then moves to the temporal lobe, followed by the frontal lobe.

\section{INFLUENCE OF LIFESTYLE ON BRAIN DEVELOPMENT}

\subsection{Sleeping Habits and Brain Development}

Recent studies have suggested that sleep is associated with hippocampal function and structure, although the role of sleep remains debatable. For example, one major theory proposes that memory consolidation occurs predominantly 
during sleep, when the hippocampus sends information from the memory to the neocortex for permanent storage [67]. Additionally, sleep deprivation has been shown to reduce the proliferation of cells and to suppress neurogenesis in the rat hippocampus [68, 69]. Even human patients with primary insomnia showed significant reductions in hippocampal volume [70]. Thus, because there is a correlation between sleep and the hippocampus in both animals and human adults, and because the influence of chronic sleep loss on the cognition of healthy children has been examined [71], there may be significant correlations between sleep and hippocampal volume in healthy children. Indeed, we recently reported a correlation between sleep duration and hippocampal gray matter volume using MR images of a large number of healthy children, aged 5-18 years. We found that the volume of the bilateral hippocampal body significantly positively correlated with the duration of sleep during weekdays after adjusting for age, sex, and intracranial volume and after performing small-volume correction of the hippocampal ROI [72]. Although the mechanisms underlying this significant positive correlation have not been clarified, the findings of several studies in rats and humans support these results. Thus, sleep may be necessary for neurogenesis and synaptic reorganization in the human hippocampus. These findings advance our understanding of the importance of sleep habits in the daily lives of children.

\subsection{Breakfast Habits and Brain Development}

Because brain development continues throughout childhood and adolescence, an adequate diet during these periods is thought to affect brain development and cognitive function. Indeed, recent studies have shown that eating breakfast has an immediate positive effect on cognitive function in children [73-75], and that skipping breakfast affects their problem solving [76], short-term memory [76], and attention [77]. In addition, several studies on school breakfast programs have shown positive long-term effects of breakfast on the cognitive performance of well-nourished children [78, 79]. Moreover, there is a significant positive correlation between regional brain gray matter volume in several regions such as the prefrontal cortex [83], orbitofrontal cortex [80], and cingulate gyrus [80,81] and cognitive function, such as intelligence quotient (IQ) [8083]. Thus, because of the correlation between breakfast staple type and several cognitive functions, and between cognitive function and gray matter volume, correlations may also exist between breakfast staple type and gray matter volume in children. Recently, we reported that gray matter volume related to daily breakfast habits for a large number of healthy children aged 5-18 years [84]. Since boiled white rice and white bread are the two major breakfast staples in Japan, we divided subjects depending on their breakfast staple. The rice group consisted of subjects who habitually ate boiled white rice for breakfast, while white bread was habitually eaten for breakfast by the "bread group". We found that the rice group had significantly larger regional gray matter volumes in an anatomical cluster that included the left superior temporal gyrus, the left inferior frontal gyrus, and the bilateral caudate nuclei after adjusting for age, gender, intracranial volume, socioeconomic status, average frequency of eating breakfast, and number of side dishes eaten for breakfast [84]. Thus, long term dietary habits influence gray matter development. Although the mechanisms remain to be uncovered, the glycemic properties of the staples may affect these results. The main difference between the components of boiled white rice and white bread is in their respective Glycemic Index (GI), which measures glycemic properties [85]. In general, high GI foods are rapidly digested low-fiber high carbohydrate foods that cause an initial sharp blood glucose peak, with overall lower circulating blood glucose $2 \mathrm{~h}$ later. Conversely, low GI foods cause a lower blood glucose peak, and generally result in a more sustained blood sugar response, resulting in lower fluctuation in blood glucose level and more stable and efficient glucose supply to the brain compared with high GI food. The GI of Japanese boiled white rice is reported to be lower than that of white bread (boiled white rice: white bread $=68: 100$ ) [86], suggesting that boiled white rice provides a more stable and efficient glucose supply than white bread. Because a major portion of the glucose consumed by the brain is used for the maintenance of resting membrane potential in neurons [63], stable and efficient glucose supply is important. In addition, cerebral metabolic rates of glucose utilization are approximately two times higher in children, compared with adults [46], because the mean number of synapses per neuron increases in pre-adolescence $[6,8]$. Therefore, an efficient supply of glucose is thought to be especially important for brain maturation in children and, thus, the breakfast staple type is thought to affect pediatric gray matter volumes.

\section{UNRESOLVED ISSUES}

The trajectories of gray/white matter volume and white matter microstructure with age have been clarified in healthy children. However, most studies have used a cross-sectional design, because it is easier to analyze the correlation between brain measures such as gray matter volume and age within a wide age range, using a large number of subjects, than using longitudinal analysis. However, the estimation of age-related changes by a cross-sectional design may be confounded by individual differences in brain size. In contrast, longitudinal analyses can identify subtle changes in brain volume over time, because individual variability in brain size does not obscure such changes. Indeed, longitudinal studies have shown that there are substantial differences between the magnitude of the average annual change in gray matter volume derived from longitudinal studies and that derived from cross-sectional studies in an adult aging study $[87,88]$. Therefore, longitudinal studies are needed to clarify the trajectory of gray and white matter with age in healthy children more efficiently. Recently, several longitudinal studies correlated cortical thickness with age [22], or white matter microstructure with age [89]. Those studies clarified more detailed brain development from the context of gray matter than white matter. However, few studies have focused on longitudinal developmental changes in brain perfusion. In addition, longitudinal effects of lifestyle on brain development have not been fully clarified yet.

As regards lifestyle factors that affect brain development in healthy children, we demonstrated that sleeping and breakfast habits are likely to affect brain development. However, several other factors may also influence brain development. For example, exercise training is associated with increased serum levels of brain derived neurotropic factor (BDNF), resulting in an increase in gray matter 
volume of the adult hippocampus [90]. Therefore, it is thought that exercise training may positively influence brain development in healthy children.

In addition, recent studies have shown that genetic factors affect gray matter volume. For example, a Val66Met single nucleotide polymorphism (SNP) in the BDNF gene is associated with hippocampal volume [91, 92]. Sleeping habits also affect hippocampal gray matter volume [72]. Therefore, studying the interaction of genetic factors with lifestyle in brain development will facilitate our understanding of brain development in healthy children.

\section{CONCLUSIONS}

Gray matter volume increases with age and then decreases, and the age of peak volume differs among brain regions in the first and second decades of life. White matter volume increases mostly linearly during those periods. As for fractional anisotropy, most regions show an exponential trajectory with age during those periods. In addition, we have shown that several lifestyle factors such as sleeping habits may affect brain development in healthy children. Future studies should increase our understanding of a number of uninvestigated important issues that were discussed here.

\section{CONFLICT OF INTEREST}

The authors confirm that this article content has no conflicts of interest.

\section{ACKNOWLEDGEMENTS}

We thank H. Hashizume, B. Thyreau, Y. Sassa, H. Takeuchi, M. Asano, K. Asano, Y. Kotozaki, R. Nouchi, and Y. Yamada for collecting MRI data and supporting data analysis, and Y. Suzuki for technical support. We also thank H. Fukuda for advice on research introduced in this review. This work was supported by the Ministry of Education, Culture, Sports, Science and Technology Grant-in-Aid for Young Scientists (B) (grant number 20790875).

\section{REFERENCES}

[1] Lenroot RK, Gogtay N, Greenstein DK, et al. Sexual dimorphism of brain developmental trajectories during childhood and adolescence. Neuroimage 2007; 36(4): 1065-73.

[2] Giedd JN, Blumenthal J, Jeffries NO, et al. Brain development during childhood and adolescence: a longitudinal MRI study. Nat Neurosci 1999; 2(10): 861-3.

[3] Gogtay N, Giedd JN, Lusk L, et al. Dynamic mapping of human cortical development during childhood through early adulthood. Proc Natl Acad Sci USA 2004; 101(21): 8174-9.

[4] Johnson MH. Functional brain development in humans. Nat Rev Neurosci 2001; 2(7): 475-83.

[5] Thatcher RW. Cyclic cortical reorganization during early childhood. Brain Cogn 1992; 20(1): 24-50.

[6] Huttenlocher PR, Dabholkar AS. Regional differences in synaptogenesis in human cerebral cortex. J Comp Neurol 1997; 387(2): 167-78.

[7] Huttenlocher PR, de Courten C, Garey LJ, Van der Loos H. Synaptogenesis in human visual cortex--evidence for synapse elimination during normal development. Neurosci Lett 1982; 33(3): 247-52.

[8] Huttenlocher PR. Synaptic density in human frontal cortex developmental changes and effects of aging. Brain Res 1979; 163(2): 195-205.
[9] Boddaert N, Chabane N, Gervais H, et al. Superior temporal sulcus anatomical abnormalities in childhood autism: a voxel-based morphometry MRI study. Neuroimage 2004; 23(1): 364-9.

[10] Bonilha L, Cendes F, Rorden C, et al. Gray and white matter imbalance--typical structural abnormality underlying classic autism? Brain Dev 2008; 30(6): 396-401.

[11] Jiao Y, Chen R, Ke X, Chu K, Lu Z, Herskovits EH. Predictive models of autism spectrum disorder based on brain regional cortical thickness. Neuroimage 2010; 50(2): 589-99.

[12] Takeuchi H, Taki Y, Sassa Y, et al. Regional gray matter density associated with emotional intelligence: evidence from voxel-based morphometry. Hum Brain Mapp 2011; 32(9): 1497-510.

[13] Courchesne E, Karns CM, Davis HR, et al. Unusual brain growth patterns in early life in patients with autistic disorder: an MRI study. Neurology 2001; 57(2): 245-54.

[14] Jernigan TL, Press GA, Hesselink JR. Methods for measuring brain morphologic features on magnetic resonance images: validation and normal aging. Arch Neurol 1990; 47(1): 27-32.

[15] Jernigan TL, Tallal P. Late childhood changes in brain morphology observable with MRI. Dev Med Child Neurol 1990; 32(5): 379-85.

[16] Jernigan TL, Trauner DA, Hesselink JR, Tallal PA. Maturation of human cerebrum observed in vivo during adolescence. Brain 1991; 114(PT 5): 2037-49.

[17] Pfefferbaum A, Mathalon DH, Sullivan EV, Rawles JM, Zipursky $\mathrm{RB}$, Lim KO. A quantitative magnetic resonance imaging study of changes in brain morphology from infancy to late adulthood. Arch Neurol 1994; 51(9): 874-87.

[18] Paus T. Mapping brain maturation and cognitive development during adolescence. Trends Cogn Sci 2005; 9(2): 60-8.

[19] Wilke M, Krageloh-Mann I, Holland SK. Global and local development of gray and white matter volume in normal children and adolescents. Exp Brain Res 2007; 178(3): 296-307.

[20] Guo X, Chen C, Chen K, Jin Z, Peng D, Yao L. Brain development in Chinese children and adolescents: a structural MRI study. Neuroreport 2007; 18(9): 875-80.

[21] Ashburner J, Friston KJ. Voxel-based morphometry--the methods. Neuroimage 2000; 11(6 PT 1): 805-21.

[22] Shaw P, Kabani NJ, Lerch JP, et al. Neurodevelopmental trajectories of the human cerebral cortex. J Neurosci 2008; 28(14): 3586-94.

[23] Tamnes CK, Ostby Y, Fjell AM, Westlye LT, Due-Tonnessen P, Walhovd KB. Brain maturation in adolescence and young adulthood: regional age-related changes in cortical thickness and white matter volume and microstructure. Cereb Cortex 2010; 20(3): 534-48.

[24] Ostby Y, Tamnes CK, Fjell AM, Westlye LT, Due-Tonnessen P, Walhovd KB. Heterogeneity in subcortical brain development: A structural magnetic resonance imaging study of brain maturation from 8 to 30 years. J Neurosci 2009; 29(38): 11772-82.

[25] Akaike H. A new look at statistical model identification. IEEE Trans Automatic Control 1974; 19(6):716-23.

[26] Taki Y, Hashizume H, Thyreau B, et al. Linear and curvilinear correlations of brain gray matter volume and density with age using voxel-based morphometry with the Akaike information criterion in 291 healthy children. Hum Brain Mapp 2012; (In press).

[27] Lebel C, Walker L, Leemans A, Phillips L, Beaulieu C. Microstructural maturation of the human brain from childhood to adulthood. Neuroimage 2008; 40(3): 1044-55.

[28] Paus T, Collins DL, Evans AC, Leonard G, Pike B, Zijdenbos A. Maturation of white matter in the human brain: a review of magnetic resonance studies. Brain Res Bull 2001; 54(3): 255-66.

[29] Sowell ER, Trauner DA, Gamst A, Jernigan TL. Development of cortical and subcortical brain structures in childhood and adolescence: a structural MRI study. Dev Med Child Neurol 2002; 44(1): 4-16.

[30] Le Bihan D. Looking into the functional architecture of the brain with diffusion MRI. Nat Rev Neurosci 2003; 4(6): 469-80.

[31] Pierpaoli C, Basser PJ. Toward a quantitative assessment of diffusion anisotropy. Magn Reson Med 1996; 36(6): 893-906. Erratum appears in Magn Reson Med 1997; 37(6):972.

[32] Beaulieu C. The basis of anisotropic water diffusion in the nervous system - a technical review. NMR Biomed 2002; 15(7-8): 435-55.

[33] Mori S, Zhang J. Principles of diffusion tensor imaging and its applications to basic neuroscience research. Neuron 2006; 51(5): 527-39. 
[34] Wozniak JR, Lim KO. Advances in white matter imaging: a review of in vivo magnetic resonance methodologies and their applicability to the study of development and aging. Neurosci Biobehav Rev 2006; 30(6): 762-74.

[35] Schmithorst VJ, Wilke M, Dardzinski BJ, Holland SK. Correlation of white matter diffusivity and anisotropy with age during childhood and adolescence: a cross-sectional diffusion-tensor MR imaging study. Radiology 2002; 222(1): 212-8.

[36] Barnea-Goraly N, Menon V, Eckert M, et al. White matter development during childhood and adolescence: a cross-sectional diffusion tensor imaging study. Cereb Cortex 2005; 15(12): 184854.

[37] Bonekamp D, Nagae LM, Degaonkar M, et al. Diffusion tensor imaging in children and adolescents: reproducibility, hemispheric, and age-related differences. Neuroimage 2007; 34(2): 733-42.

[38] Muetzel RL, Collins PF, Mueller BA, M Schissel A, Lim KO, Luciana M. The development of corpus callosum microstructure and associations with bimanual task performance in healthy adolescents. Neuroimage 2008; 39(4): 1918-25.

[39] Mukherjee P, Miller JH, Shimony JS, et al. Diffusion-tensor MR imaging of gray and white matter development during normal human brain maturation. AJNR Am J Neuroradiol 2002; 23(9): 1445-56.

[40] Schneider JF, Il'yasov KA, Hennig J, Martin E. Fast quantitative diffusion-tensor imaging of cerebral white matter from the neonatal period to adolescence. Neuroradiology 2004; 46(4): 258-66.

[41] Zhang L, Thomas KM, Davidson MC, Casey BJ, Heier LA, Ulug AM. MR quantitation of volume and diffusion changes in the developing brain. AJNR Am J Neuroradiol 2005; 26(1): 45-9.

[42] Ben Bashat D, Ben Sira L, Graif M, et al. Normal white matter development from infancy to adulthood: comparing diffusion tensor and high $\mathrm{b}$ value diffusion weighted MR images. J Magn Reson Imaging 2005; 21(5): 503-11.

[43] Taki Y, Thyreau B, Hashizume H, et al. Linear and curvilinear correlations of brain white matter volume, fractional anisotropy, and mean diffusivity with age using voxel-based and region-ofinterest analyses in 246 healthy children. Hum Brain Mapp 2012; (In press).

[44] Klingberg T, Vaidya CJ, Gabrieli JD, Moseley ME, Hedehus M. Myelination and organization of the frontal white matter in children: a diffusion tensor MRI study. Neuroreport 1999; 10(13): 2817-21

[45] Takeuchi H, Sekiguchi A, Taki Y, et al. Training of working memory impacts structural connectivity. J Neurosci 2010; 30(9): 3297-303.

[46] Chugani HT. A critical period of brain development: studies of cerebral glucose utilization with PET. Prev Med 1998; 27(2): 1848 .

[47] Gupta SK, Ratnam BV. Cerebral perfusion abnormalities in children with autism and mental retardation: a segmental quantitative SPECT study. Indian Pediatr 2009; 46(2): 161-4.

[48] Burroni L, Orsi A, Monti L, Hayek Y, Rocchi R, Vattimo AG. Regional cerebral blood flow in childhood autism: a SPET study with SPM evaluation. Nucl Med Commun 2008; 29(2): 150-6.

[49] Oner O, Oner P, Aysev A, Kucuk O, Ibis E. Regional cerebral blood flow in children with ADHD: changes with age. Brain Dev 2005; 27(4): 279-85

[50] Williams DS, Detre JA, Leigh JS, Koretsky AP. Magnetic resonance imaging of perfusion using spin inversion of arterial water. Proc Natl Acad Sci USA 1992; 89(1): 212-6. Erratum appears in Proc Natl Acad Sci U S A 1992; 89(9): 4220.

[51] Detre JA, Alsop DC, Vives LR, Maccotta L, Teener JW, Raps EC. Noninvasive MRI evaluation of cerebral blood flow in cerebrovascular disease. Neurology 1998; 50(3): 633-41.

[52] Alsop DC, Detre JA, Grossman M. Assessment of cerebral blood flow in Alzheimer's disease by spin-labeled magnetic resonance imaging. Ann Neurol 2000; 47(1): 93-100.

[53] Chalela JA, Alsop DC, Gonzalez-Atavales JB, Maldjian JA, Kasner SE, Detre JA. Magnetic resonance perfusion imaging in acute ischemic stroke using continuous arterial spin labeling. Stroke 2000; 31(3): 680-7.

[54] Chao LL, Buckley ST, Kornak J, et al. ASL perfusion MRI predicts cognitive decline and conversion from MCI to dementia. Alzheimer Dis Assoc 2010; 24(1): 19-27.
[55] Du AT, Jahng GH, Hayasaka S, et al. Hypoperfusion in frontotemporal dementia and Alzheimer disease by arterial spin labeling MRI. Neurology 2006; 67(7): 1215-20.

[56] Dobbing J, Sands J. Quantitative growth and development of human brain. Arch Dis Child 1973; 48(10): 757-67.

[57] Schoning M, Staab M, Walter J, Niemann G. Transcranial color duplex sonography in childhood and adolescence: age dependence of flow velocities and waveform parameters. Stroke 1993; 24(9): 1305-9.

[58] Wang J, Licht DJ. Pediatric perfusion MR imaging using arterial spin labeling. Neuroimaging Clin N Am 2006; 16(1): 149-67.

[59] Biagi L, Abbruzzese A, Bianchi MC, Alsop DC, Del Guerra A, Tosetti M. Age dependence of cerebral perfusion assessed by magnetic resonance continuous arterial spin labeling. J Magn Reson Imaging 2007; 25(4): 696-702.

[60] Ye FQ, Berman KF, Ellmore T, et al. H(2)(15)O PET validation of steady-state arterial spin tagging cerebral blood flow measurements in humans. Magn Reson Med 2000; 44(3): 450-6.

[61] Taki Y, Hashizume H, Sassa Y, et al. Correlation between gray matter density-adjusted brain perfusion and age using brain MR images of 202 healthy children. Hum Brain Mapp 2011; 32(11): 1973-85.

[62] Ito H, Kanno I, Fukuda H. Human cerebral circulation: positron emission tomography studies. Ann Nucl Med 2005; 19(2): 65-74.

[63] Mata M, Fink DJ, Gainer H, et al. Activity-dependent energy metabolism in rat posterior pituitary primarily reflects sodium pump activity. J Neurochem 1980; 34(1): 213-5.

[64] Newberg AB, Wang J, Rao H, et al. Concurrent CBF and CMRGlc changes during human brain activation by combined fMRI-PET scanning. Neuroimage 2005; 28(2): 500-6.

[65] Fox PT, Raichle ME. Focal physiological uncoupling of cerebral blood flow and oxidative metabolism during somatosensory stimulation in human subjects. Proc Natl Acad Sci USA 1986; 83(4): 1140-4.

[66] Fox PT, Raichle ME, Mintun MA, Dence C. Nonoxidative glucose consumption during focal physiologic neural activity. Science 1988; 241(4864): 462-4

[67] Axmacher N, Draguhn A, Elger CE, Fell J. Memory processes during sleep: beyond the standard consolidation theory. Cell Mol Life Sci 2009; 66(14): 2285-97.

[68] Guzman-Marin R, Suntsova N, Stewart DR, Gong H, Szymusiak R, McGinty D. Sleep deprivation reduces proliferation of cells in the dentate gyrus of the hippocampus in rats. J Physiol 2003; 549(PT 2): $563-71$

[69]. Guzman-Marin R, Suntsova N, Methippara M, Greiffenstein R, Szymusiak R, McGinty D. Sleep deprivation suppresses neurogenesis in the adult hippocampus of rats. Eur $\mathrm{J}$ Neurosci 2005; 22(8): 2111-6.

[70] Riemann D, Voderholzer U, Spiegelhalder K, et al. Chronic insomnia and MRI-measured hippocampal volumes: a pilot study. Sleep 2007; 30(8): 955-8.

[71] Jan JE, Reiter RJ, Bax MC, Ribary U, Freeman RD, Wasdell MB. Long-term sleep disturbances in children: a cause of neuronal loss. Eur J Paediatr Neurol 2010; 14(5): 380-90.

[72] Taki Y, Hashizume H, Thyreau B, et al. Sleep duration during weekdays affects hippocampal gray matter volume in healthy children. Neuroimage 2012; 60(1): 471-5.

[73] Murphy JM, Pagano ME, Nachmani J, Sperling P, Kane S, Kleinman RE. The relationship of school breakfast to psychosocial and academic functioning: cross-sectional and longitudinal observations in an inner-city school sample. Arch Pediatr Adolesc Med 1998; 152(9): 899-907.

[74] Pollitt E, Mathews R. Breakfast and cognition: an integrative summary. Am J Clin Nutr 1998; 67(4): 804S-13S.

[75] Vaisman N, Voet H, Akivis A, Vakil E. Effect of breakfast timing on the cognitive functions of elementary school students. Arch Pediatr Adolesc Med 1996; 150(10): 1089-92.

[76] Pollitt E, Lewis NL, Garza C, Shulman RJ. Fasting and cognitive function. J Psychiatr Res 1982; 17(2): 169-74.

[77] Conners CK, Blouin AG. Nutritional effects on behavior of children. J Psychiatr Res 1982; 17(2): 193-201.

[78] Vera Noriega JA, Dominguez ISE, Pena RMO, Montiel Carbajal MM. Evaluation of the effects of a school breakfast program on attention and memory. [Spanish]. Arch Latinoam Nutr 2000; 50(1): $35-41$. 
[79] Shemilt I, Harvey I, Shepstone L, et al. A national evaluation of school breakfast clubs: evidence from a cluster randomized controlled trial and an observational analysis. Child Care Health Dev 2004; 30(5): 413-27.

[80] Frangou S, Chitins X, Williams SC. Mapping IQ and gray matter density in healthy young people. Neuroimage 2004; 23(3): 800-5.

[81] Wilke M, Sohn JH, Byars AW, Holland SK. Bright spots: correlations of gray matter volume with IQ in a normal pediatric population. Neuroimage 2003; 20(1): 202-15.

[82] Haier RJ, Jung RE, Yeo RA, Head K, Alkire MT. Structural brain variation and general intelligence. Neuroimage 2004; 23(1): 42533 .

[83] Shaw P, Greenstein D, Lerch J, et al. Intellectual ability and cortical development in children and adolescents. Nature 2006; 440(7084): 676-9.

[84] Taki Y, Hashizume H, Sassa Y, et al. Breakfast staple types affect brain gray matter volume and cognitive function in healthy children. PLoS One 2010; 5(12): e15213.

[85] Jenkins DJ, Wolever TM, Taylor RH, et al. Glycemic index of foods: a physiological basis for carbohydrate exchange. Am J Clin Nutr 1981; 34(3): 362-6.
[86] Foster-Powell K, Holt SH, Brand-Miller JC. International table of glycemic index and glycemic load values: 2002. Am J Clin Nutr 2002; 76(1): 5-56

[87] Raz N, Lindenberger U, Rodrigue KM, et al. Regional brain changes in aging healthy adults: general trends, individual differences and modifiers. Cereb Cortex 2005; 15(11): 1676-89.

[88] Taki Y, Kinomura S, Sato K, Goto R, Kawashima R, Fukuda H. A longitudinal study of gray matter volume decline with age and modifying factors. Neurobiol Aging 2011; 32(5): 907-15.

[89] Lebel C, Beaulieu C. Longitudinal development of human brain wiring continues from childhood into adulthood. J Neurosci 2011; 31(30): 10937-47.

[90] Erickson KI, Voss MW, Prakash RS, et al. Exercise training increases size of hippocampus and improves memory. Proc Natl Acad Sci USA 2011; 108(7): 3017-22.

[91] Toro R, Chupin M, Garnero L, et al. Brain volumes and Val66Met polymorphism of the BDNF gene: local or global effects. Brain Struct 2009; 213(6): 501-9. Erratum appears in Brain Struct Funct. 2009; 214(1): 87 .

[92] Pezawas L, Verchinski BA, Mattay VS, et al. The brain-derived neurotrophic factor val66met polymorphism and variation in human cortical morphology. J Neurosci 2004; 24(45): 10099-102.

Received: July 10, 2012

Revised: August 28,2012

Accepted: September 02, 2012

(C) Taki and Kawashima; Licensee Bentham Open.

This is an open access article licensed under the terms of the Creative Commons Attribution Non-Commercial License (http://creativecommons.org/licenses/by$\mathrm{nc} / 3.0 /)$, which permits unrestricted, non-commercial use, distribution and reproduction in any medium, provided the work is properly cited. 